\title{
CDISC SDTM Contact Setting Terminology
}

National Cancer Institute

\section{Source}

National Cancer Institute. CDISC SDTM Contact Setting Terminology. NCI Thesaurus.

Code C102588.

Terminology associated with the contact setting codelist of the Clinical Data Interchange Standards Consortium (CDISC) Study Data Tabulation Model (SDT M). 